\title{
Freshwater diatom biogeography and the genus Luticola: An extreme case of endemism in Antarctica
}

\author{
Van de Vijver Bart' 1,2 J. Patrick Kociolek ${ }^{3,4}$, Katerina Kopalová ${ }^{5}$, Sarah E. Hamsher ${ }^{3}$, Tyler J. Kohler ${ }^{5,6}$, \\ Pete Convey ${ }^{7}$ and Diane M. McKnight ${ }^{6}$ \\ Botanic Garden Meise, Department of Bryophyta \& Thallophyta, Nieuwelaan 38, B-1860 Belgium \\ E-mail: bart.vandevijver@plantentuinmeise.be \\ 2 University of Antwerp, Department of Biology, ECOBE, Universiteitsplein 1, B-2610 Wilrijk, \\ Antwerpen, Belgium \\ 3 Museum of Natural History, UCB 218 , University of Colorado, Boulder, CO 80309, USA \\ ${ }^{4}$ Department of Ecology and Evolutionary Biology, University of Colorado, Boulder, CO 80309 USA \\ ${ }^{5}$ Charles University in Prague, Faculty of Science, Department of Ecology, Vininá 7, 12844 Prague 2, \\ Czech Republic \\ ${ }^{6}$ University of Colorado, Institute of Arctic \& Alpine Research, Boulder, CO 80309 USA \\ 7 British Antarctic Survey, High Cross, Madingley Road, Cambridge, CB3 OET, United Kingdom
}

Historic views on levels of endemism in the Antarctic region have characterized the region as a frozen desert with little diversity and low endemism. More recent studies however have uncovered an endemism in this region that may be much greater than previously expected in several groups. Assessing levels of endemism in the Antarctic region has become particularly important for microbes, in the light of the ongoing debate regarding the possible cosmopolitan nature of small species.

In order to analyze the degree of endemism of the limno-terrestrial genus Luticola in this region, all taxonomical results based on a modern fine-grained taxonomy have been synthesized for Luticola in the entire Antarctic region, as well as southern areas of South America. We examined recent and historical taxonomic treatments of freshwater diatoms for the Antarctic region, and compiled data for the number of endemic species and their distributions. Over 200 species of Luticola are currently known worldwide. Almost $20 \%$ occur in freshwater habitats in the Antarctic region. Of these 43 species, 42 are endemic to the region, with maritime Antarctic localities being the most species and endemic-rich $(28,23$, respectively), followed by continental Antarctica (14, 9 respectively) and the sub-Antarctic islands (8, 6, respectively). Luticola has one of the highest percentages of endemism in Antarctica of any known diatom genus, in terms of total number of species (=taxon endemism) as well as a percentage of the entire genus (=phylogenetic endemism). These numbers of endemics for Luticola are compared with other groups of terrestrial and freshwater organisms, showing that the genus has one of the highest, if not the highest levels of endemicity in Antarctica. The timing of the diversification of Luticola has not been established, but the oldest known fossils of the genus date only to the Holocene, suggesting that diversification processes in Luticola are rapid, and that single or multiple invasions of the region may have occurred over a very short geologic timescale. Understanding the origin and evolution of endemic species in Antarctica will allow a better understanding of the baseline and impacts during a time of large-scale environmental changes in southern latitudes. 